Lastly, there is a contrivance whereby a "weight jerks violently upward the feet of a sleeper, who is thus awakened and goes about his business". Whether this was seriously meant one cannot say; many similar devices are familiar to students of the history of inventions. 'The particular interest of Leonardo's apparatus is that it is an early example of a relay mechanism.

Concerning the paintings, it would be difficult to add anything to the notes in the catalogue, particularly as they include selected references to the vast literature that has grown up around the subject; but the smile of Mona Lisa, often called mysterious, is a small point of interest unmentioned in the notes. A like smile, so faint as to be barely perceptible, is to be seen in "La Belle Ferronnière" (Louvre), and again, a little stronger, in the "Lady with an Ermine" (Warsaw, Czartoryski Museum). This smirk annoys some, who point out that the women in religious pictures smile in a normal manner (cf. "The Virgin and Child with St. Anne and St. John": No. 109). It should be borne in mind, however, that Leonardo was the greatest painter of his time, and that his sitters, besides being paintable, were wealthy and fashionable. Now the fashionable smile of the ladies of the Renaissance was that painted by Leonardo; in their books of etiquette it was laid down that they should close the mouth at the right corner and open it on the left as though they were smiling secretly. But the fashionable smile of Mona Lisa was not suitable for sacred art ; neither, so far as I am aware, did Leonardo ever depict it there. We have Vasari's authority that while Leonardo was painting Mona Lisa, "he engaged people to play and sing and jesters to keep her merry. . . . This figure . . . had such a pleasant smile that it seemed divine rather than human, and was considered marvellous, an exact copy of Nature". The fame of the smile has not diminished after four centuries and a half; but, "an exact copy of Nature" ? How that phrase illuminates the gulf extending between the High Renaissance and the present.

\section{THE BRITISH CONTRIBUTION TO TELEVISION}

$\mathrm{D}$ URING April 28-May 3, the Institution of Electrical Engineers held a convention on "The British Contribution to Television", which was attended by more than 1,300 registered members, including 137 delegates from twenty-one different countries. The programme comprised ten sessions, at which more than eighty technical papers were presented and discussed, and a number of visits to such places as the B.B.C. television stations and studios, the Post Office Research Station and some dozen firms in the radio industry. A few social gatherings were also arranged, including a Television Ball and Dinner at Grosvenor House, London.

The convention was opened by the Right Hon. Lord Woolton, who surveyed briefly the development of television in Great Britain, starting from the suggestion put forward in 1908 by Mr. A. A. Campbell Swinton to use beams of cathode rays to convert the rapid variations of light and shade into electric impulses at one end, and to reverse the process at the other end of the system. He referred to the facts that the first public television service in the world started in London in 1936 ; and that the completion of the present plan of installing five high-power and five medium-power stations in Britain will make the television service available to about 88 per cent of the population of the United Kingdom. While we can scarcely expect to emulate the achievements of the United States in their spectacular development of television during the past five years or so, it is gratifying to observe that the radio industry in Britain has taken full advantage of the opportunities provided by the corresponding development here. Many firms must now have, in production, cathode ray tubes and other components assembled in television receivers, on a scale which would have been deemed impracticable a few years ago.

After a brief expression of thanks by Sir John Hacking, president of the Institution, who also welcomed Dr. Donald Sinclair, president of the Institute of Radio Engineers, New York, and other distinguished visitors and guests, an address on "Ielevision Development" was presented by Sir Noel Ashbridge, then the director of technical services of the British Broadcasting Corporation. He traced the growth of the television service in Great Britain from the early experiments of J. L. Baird, with a lowdefinition system of 30 lines per frame and $12 \frac{1}{2}$ frames per sec., to the adoption in 1937 of the system developed by the Marconi-E.M.I. Co., using the technical standards of 405 lines per picture, 25 pictures (50 frames) per sec. with double interlaced scanning and positive modulation. While these standards are practically identical with those in use to-day, there has been much discussion at international committees during the past two years on the relative merits of this and other standards, differing mainly in the use of a greater number of lines per picture. As Sir Noel pointed out, for any improvement to be obtained by the use of more scanning lines, the band-width available at every point in the chain of transmission and reception must be increased correspondingly, with increase in costs all round. If this increased band-width is not available, a worse picture may result than that given by the present system using a smaller number of lines. It is greatly to be regretted that little progress has been made towards internationally agreed standards for television* services; and there are, so far, four different specifications for black-and-white television in use, or shortly to be used, for broadcasting.

Looking to the future, Sir Noel said that colour is almost certain to be the most spectacular development in the next few years, and there are two systems sufficiently developed in the United States to merit serious and immediate consideration. No system has, however, been very definitely established on a publicservice basis; but it is certain that the costs will be greater than with the black-and-white system in all respects, namely, programme production, technical operation and capital cost. While the use of colour may not be justified in all cases, there is no reason why colour television should not in the end give truer reproduction than colour films have in the past.

Reference was also made to the possibilities of stereoscopic television, with or without colour, and to the other applications of television, such as surgery, whereby a considerable number of people can witness a demonstration under conditions in which limited accommodation would make this impracticable otherwise.

At the second session of the convention, a broad historical review of the development of television was 
presented by Messrs. G. R. M. Garratt and A. H. Mumford. The history of television may be said to date from the observations, made by Becquerel in 1839, that when two electrodes are immersed in a suitable electrolyte and illuminated by a beam, an electromotive force is generated between the electrodes. The next stage was the discovery by Willoughby Smith in 1873 of the effect of light on the resistance of selenium. This discovery had no immediate sequel, but the era of stimulated progress which followed Bell's invention of the telephone in 1875 provided the background for numerous ideas for 'seeing by electricity'. Many of the resulting inventions were impracticable, chiefly because other discoveries and developments essential to the realization of the main ideas had not been made. From these beginnings, this paper traced the development of television following the suggestion of Campbell Swinton referred to above, and the introduction of the thermionic valve into radio practice. The presentation of the paper was accompanied by a demonstration of the mechanical system of television reception developed by Baird and used in the early experiments of the B3.B.C.

The third session was introduced by Mr. I). C. Birkinshaw with a paper entitled "r'elevision P'rogramme Origination : the Engineering Technique". This paper, which was supported by fourteen others, surveyed the development of the engineering techniques associated with the origination of television programmes in Great Britain. Both studio and outside broadcast equipment were dealt with ; much detailed design information from experienced authors is contained in these papers.

At the following session, Mr. P. A. 'T. Bevan reviewed the television transmitting scheme by which the British Broadcasting Corporation hopes to serve the greater part of the population of the United Kingdom. The basic factors underlying the choice of the scheme are discussed in the paper, together with the arrangements for dividing the available frequency-band into five separate channels. The general design of the complete equipment used at the transmitting stations is described with particular reference to the different types of vision and sound transmitters. The four supporting papers describe some of the special equipment features, including the aerial systems, in greater detail.

A survey of British research on wave propagation with particular reference to television was presented at the fifth session by Dr. R. L. Smith-Rose, and his remarks were amplified in four supporting papers. In this review emphasis was placed on the fact that the planning and successful operation of a national television service involves a somewhat detailed understanding of the mode of propagation of the radio waves concerned. For the service to be successful, a satisfactory ratio of the wanted signal to the prevailing noise or other interfering signals must be established within the reception area of each transmitting station. In addition, in view of the necessity of operating two or more stations in the same frequency-channel, a statistical knowledge of the propagation of the waves concerned to considerable distances is necessary in order to avoid mutual interference of the different transmitting stations. Furthermore, the use of radio links at extremely high frequencies for the exchange of programmes between stations involves a knowledge of the vagaries of the propagation of the very short waves concerned under varying atmospheric conditions. The papers pre- sented at this session contain the results of many years work in this field, and form a basis of fundamental knowledge which has enabled the planning and establishment of a television service to be carried out so successfully in Britain.

With two introductory papers and eighteen supporting contributions, the next session dealt with point-to-point transmission. Dr. A. R. A. Rendall and $\mathrm{Mr} . \mathrm{W} . \mathrm{N}$. Anderson described the arrangements used for temporary linkages for outside broadcasting purposes ; while Mr. H. Faulkner spoke on permanent point-to-point links for relaying television programmes between transmitting stations. The object of these links is to provide a reliable system of transmitting vision signals involving a band-width of $3 \mathrm{Mc} / \mathrm{s}$. over which the electrical characteristics are uniform and stable to a high degree. Experience in Great Britain has shown that excellent results can be obtained either by coaxial cable or by radio transmission, so that the choice between the two systems is largely a question of economics. The present advantage appears to be with the cable links on combined television and telephony routes; but, when radio links have been developed for the simultaneous transmission of television and multi-channel tolephony, this advantage will be nullified. An item of interest in this connexion is that the travelling-wave tube, produced in Great Britain during the War, has found its first commercial application in the radio link between Manchester and Edinburgh. At the working frequency of $4,000 \mathrm{Mc} . / \mathrm{s}$., its high amplification and low noise-factor render an intermediate-frequency amplifier unnecessary and this reduces the overall cost of the link. The supporting papers describe in detail some of these radio and cable links and the associated equipment and testing apparatus.

The seventh session, on "Industrial Television", was outstanding in so far as the presentation was concerned. By the aid of a television link and a projection-type receiver and large screen, the authors introduced their papers from the lecture hall of the Institution of Civil Engineers, while the audience of more than six hundred watched in the adjacent Great Hall. In his survey paper, Dr. R. G. C. Williams pointed out that Great Britain has pioneered in industrial television no less than for broadcasting. Apart from the use of television for education and training and similar 'large-screen' work, an important application is to take advantage of the 'extension eye' principle in such fields as underwater television, the demonstration of surgical operations and the observation of dangerous processes. Among the eight supporting papers was one by Mr. F. Roberts and Prof. J. Z. Young entitled "The Flying-Spot Microscope". In the presentation of this, the authors demonstrated how the apparatus could give an accurate count of the thousands of minute nerve endings in a human nerve trunk, of which they showed a cross-section larger than had ever been seen before as a result of the magnification of more than half a million times with the large-screen equipment.

The next two sessions of the convention dealt in considerable detail with the problems of television reception, and especially with the design and construction of receivers, and the valves and cathoderay tubes for use therein. In addition to the two survey papers, there were fifteen supporting papers which had been prepared by experts in the various phases of the reception of television broadcasting.

In the tenth and final session, Mr. L. C. Jesty dealt with "Television as a Communications Problem", 
and laid stress on the need for conserving ether space in the transmission of television signals. This phase of the subject will become of enhanced importance when the possibility of colour television is discussed, and also in connexion with the relaying of programmes over very great distances. Ten supporting papers contribute much detailed information to this question, and two of these deal with some fundamental aspects of colour television of both a subjective and objective nature.

There is no doubt that the holding of this convention brought together a large amount of detailed and expert technical knowledge on the various aspects of television described above; and this knowledge will prove very valuable to those responsible for the future development of television everywhere. The complete proccedings of the convention, containing the addresses, the full text of all the papers and reports of the discussions, will bo published in four issues (Nos. 17 20 inclusive) of a special volume of the Proceedings of the Institution of Electrical Engineers, Part 11I A. The first of these special issues is expected to appear shortly. Those requiring copies should apply to the Institution of Electrical Engineers, Savoy Place, London, W.C.2, from whom details of the contents and subscription-rates may be obtained.

R. L. SMITH-Rose

\section{PRINCIPLES GOVERNING THE AMOUNT OF EXPERIMENTATION IN DEVELOPMENTAL WORK}

\author{
By DR. F. YATES, F.R.S. \\ Rothamsted Experimental Station
}

G REA'T BRITAIN has lagged badly behind the United States in the practical utilization of scientific discoveries. This is reflected in the demand for mon of science in the two countries. 'The recently published Fifth Annual Report of the Advisory Council on Scientific Policy ${ }^{1}$, for example, directs attention to the fact that the United States is turning out nearly three times as many men of science in proportion to the labour force as Great Britain is, and is planning further increases, particularly at the higher level. In part this lag in putting scientific discoveries to practical use is attributable to our neglect of the experiments and tests which are necessary in developmental work. These experiments differ markedly from the laboratory experiments required in pure scientific research, since their main function is to establish empirical rules of operation which are applicable under practical conditions. With the present drive for economy there is serious danger that even such facilities as are available for experimental work of this kind will bo curtailed or not used to full advantage. It is therefore important to stress that such curtailment will result in much moro substantial and immediate losses through failure to determine the best practices. Developmental work must be expanded, not contracted, if we are to survive.

It is perhaps somewhat remarkable that no very precise consideration appears to have been given to the expenditure that is justifiable in developmental work. Instead, experimenters have tended to rely on their intuitive judgment on the accuracy that should be aimed at, and are frequently influenced in this judgment by the demands, often misplaced, for economy. In its essentials the problem is very similar to that of deciding the accuracy required in a sample survey. For this latter problem I put forward the general principle that the accuracy should be such that the sum of the cost of the survey and the expected losses due to errors in the results should be minimized ${ }^{2}$. The same principle can be applied to experimental work. It is indeed here more widely applicable, since it is usually easier in experimental work to assess the losses due to errors of a given magnitude in the results.

In experimental work, however, we have at the outset to consider the type of results that are likely to emerge and the way in which they will be used. In the case of a treatment of the all-or-nothing type we may simply require a decision on whether or not to apply the treatment uniformly to the whole of the material, or to certain categories, already defined, of the material; or we may hope that the experiments themselves will reveal a way of classifying the material into categories for some of which the treatment will be profitablo and for others unprofitable. Similarly, in the case of a quantitative treatment, wo may require only to determine what uniform level of treatment gives the greatest economic return, or we may hope to divide the material into categories for which different levels of treatment will be most economic, or find some quantitative characteristic of the material which is correlated with the most economic level.

If the discovery of appropriate categories for nonuniform treatment is the aim, more elaborate experiments will often be required. We may also be prepared to sacrifice some of the smaller gains resulting from pushing the simpler type of investigation to its economic limit in the hope of obtaining the much larger gains which will result from the effective use of differential levels of treatment. For the moment, however, we will leave aside these more difficult problems, and consider the simple case in which the whole of the material is to be treated uniformly.

When a decision whether or not to apply a treatment is required application of the above principle is complicated, and we shall not discuss the matter further here. The problem is probably only soluble in terms of fiducial probability, using the sequential approach, and then with difficulty. It is essentially that propounded by Wald in his "Statistical Decision Functions"3. When the most economic level has to be determined, on the other hand, the solution is very simple, and reveals a number of features of general interest.

At the outset it will be well to make clear exactly what is meant by the concept of expected loss due to errors in the results. Consider, for example, the question of the use of fertilizer on an agricultural crop. If the whole of the crop is to be treated alike, the most economic level of dressing, which for convenience we will call the optimum level, will be the level at which the cost of a further small increment of dressing exactly equals the value of the resultant average increment in response. In the neighbourhood of the optimum the net loss due to departure from the optimum will in general be proportional to the square of the difference of the actual dressing from the optimum. If, therefore, instead of the optimum dressing $\hat{x}$ we apply a dressing $\hat{x} \pm \delta x$ there will be a net loss of $\lambda(\delta x)^{2}$ per acre, where $\lambda$ is some constant. 